Democracia LíQUida: LA OPCIÓN DE LAS TIC PARA INCORPORAR LA PARTICIPACIÓN CIUDADANA EN INSTITUCIONES REPRESENTATIVAS

\title{
LIQUID DEMOCRACY: THE OPTION OF ICT TO INCORPORATE CITIZEN PARTICIPATION IN
} REPRESENTATIVE INSTITUTIONS

Jorge Francisco Aguirre Sala

Universidad Autónoma de Nuevo León; jorgeaguirresala@hotmail.com

\begin{tabular}{ll} 
Historia editorial & Resumen \\
\cline { 2 - 3 } $\begin{array}{l}\text { Recibido: 21-06-2017 } \\
\text { Aceptado: 28-01-2019 }\end{array}$ & $\begin{array}{l}\text { El estado del arte de la democracia en la era digital presenta las siguientes cuestio- } \\
\text { nes: ¿cuáles son las condiciones digitales para empoderar a los ciudadanos y hacer } \\
\text { efectiva su participación política?, ¿cómo conciliar la participación individual con } \\
\text { las instituciones representativas?, ¿qué transformación tiene la democracia en la } \\
\text { era digital? Como respuesta argumento que la Democracia Líquida, con los apor- } \\
\text { tes de las Tecnología de Información y Comunicación (TIC), logra la síntesis dia- }\end{array}$ \\
\hline $\begin{array}{l}\text { Palabras clave } \\
\text { Democracia deliberativa }\end{array}$ & $\begin{array}{l}\text { léctica de la democracia representativa y directa. En el argumento reviso los fun- } \\
\text { damentos y riesgos de la democracia directa, los límites de las instituciones repre- }\end{array}$ \\
$\begin{array}{l}\text { Pemocracia delegativa } \\
\text { Reciprocidad política }\end{array}$ & $\begin{array}{l}\text { sentativas y las posibilidades de la participación ciudadana. En segundo lugar, des- } \\
\text { cribo la Democracia Líquida y hago referencia a los incipientes casos empíricos } \\
\text { que han superado las insuficiencias de los modelos tradicionales (obstáculos de ex- }\end{array}$ \\
& $\begin{array}{l}\text { tensión demográfica, complejidad y especialización de los asuntos públicos). No } \\
\text { obstante, también evalúo el optimismo digital para mostrar sus avances y retos. }\end{array}$
\end{tabular}

Abstract

Keywords

Deliberative democracy

Delegative democracy

Proxies

Responsiveness
The state of the art of democracy in the digital age presents the following issues: what are the digital conditions to empower citizens and make their political participation effective? How to reconcile individual participation with representative institutions? What is the transformation of democracy in the era digital? In response, I argue that the Liquid Democracy, with the contributions of Information and Communication Technology (ICT), achieves the dialectical synthesis of representative and direct democracy. In the argument I review the foundations and risks of direct democracy, the limits of representative institutions and the possibilities of citizen participation. Second, I describe Liquid Democracy and refer to the emerging empirical cases that have overcome the inadequacies of traditional models (Obstacles to demographic extension, complexity and specialization of public affairs). The Liquid Democracy includes deliberative action too. However I also evaluated the digital optimism from theory and practice to show their challenges and progress.

Aguirre Sala, Jorge Francisco (2019). Democracia Líquida: la opción de las TIC para incorporar la participación ciudadana en instituciones representativas. Athenea Digital, 19(2), e2212. https://doi.org/10.5565/rev/athenea.2212

\section{Introducción}

En una sociedad con aspiraciones de equidad, el gobierno ha de establecerse democráticamente. Pero el gran número de ciudadanos y la composición multicultural en las sociedades actuales han multiplicado la especialización y complejidad de los problemas públicos. Ante las dificultades para establecer consensos, la democracia se decantó hacia la representación política, es decir, los ciudadanos declinan su soberanía en representantes que tomarán las decisiones públicas. No obstante, la prescripción demo- 
crática exige involucrar la mayor participación ciudadana para dar legitimidad a las decisiones gubernamentales y en ello se requieren los medios comunicativos para lograr una clara idea de la voluntad general y sus preferencias para realizar el bien común. En palabras de Rubén Galleguillo (2016): "las democracias actuales concentran básicamente su atención en torno a problemas de interacción, de elección y de delegación” (p. 51) Por ende, la esfera pública necesita auxiliarse de los avances informativos y comunicativos de la era digital.

Las nuevas Tecnologías de Información y Comunicación (TIC), aplicadas a los mecanismos de participación política, aportan una importante reestructuración a las instituciones políticas representativas. Porque si las maneras de comunicarse cambian, también se transforman los modos de deliberar y, por ende, del quehacer político. Por lo tanto, las TIC, al incidir en la interacción, elección y delegación de la esfera pública, hacen emerger las modalidades líquidas de la democracia. Es decir, potencian la comunicación fluida y permanente, conservando e incrementando la soberanía de los ciudadanos, empoderándolos en la definición de las políticas públicas y su fiscalización.

En ese contexto es necesario indagar: ¿bajo qué condiciones los instrumentos cibernéticos contribuyen a un mayor empoderamiento ciudadano al direccionar mecanismos de participación?, ¿cómo conciliar la participación directa con las estructuras de las instituciones políticas representativas?, ¿en qué medida la era digital democratiza la elaboración de las decisiones públicas?, ¿la transformación digital de la democracia es deseable? La perspectiva con que respondo a estas preguntas pretende validar al modelo líquido como la opción democratizadora por excelencia. La Democracia Líquida supera las convencionalidades del proceder representativo, rebasa las limitaciones del participativo y reorganiza lo mejor de ambos. Para sostener esto, desarrollo los siguientes apartados: la explicación de los fundamentos y riesgos de la democracia directa; el análisis de los límites de las estructuras representativas; las oportunidades participativas; la explicación del modelo líquido con sus aspectos deliberativos y su presencia en las instituciones políticas -ilustrando ello con casos empíricos que constituyen los primeros paradigmas históricos-; las dificultades y sus posibles soluciones $\mathrm{y}$; finalmente, una recapitulación conclusiva.

Huelga decir que el uso de las TIC en la Democracia Líquida, al potenciar los mecanismos de participación, aporta mejores procesos deliberativos y, con ello, establece una gestión cooperativa y compartida más allá de la mera agregación de preferencias. Es decir, contribuye a la acción comunicativa y sintetiza dialécticamente la dicotomía del modelo representativo con el participativo elevando la calidad democrática. 


\section{Democracia directa: fundamentos y riesgo}

La democracia directa nació en Grecia exclusivamente para los ciudadanos varones y libres. Sin embargo, a lo largo de la Historia requirió ajustes: el reconocimiento de la ciudadanía en cualquier sujeto con capacidad de discernimiento para votar y la igualdad de participación entre ciudadanos de distinto género.

Un ajuste histórico significativo inició con la Declaración de los derechos del hombre y del ciudadano aprobada por la Asamblea Nacional Francesa el 26 de agosto de 1789. Su artículo sexto dice: "La ley es la expresión de la voluntad general. Todos los ciudadanos tienen el derecho de concurrir a su formación personalmente o por representantes". Es decir, a diferencia del modelo clásico, desde el nacimiento de la democracia moderna se planteó la posibilidad de ejercer la soberanía de manera directa y/o representativa.

La moderna democracia directa también tuvo transformaciones a lo largo de los siglos. Las transformaciones involutivas obedecieron al incremento de los ciudadanos que dificultaron la realización de asambleas generales y con ello el esclarecimiento de la voluntad general. La complejidad y excesivo número de asuntos que deben tratarse en las asambleas, cámaras o parlamentos y la ocupada vida común de los ciudadanos provocaron el tránsito hacia la modalidad representativa. La necesidad de desahogar temas prioritarios o urgentes también transformó a la democracia directa en representativa.

La evolución más reciente de la democracia directa tiene carácter jurídico. A diferencia del origen moderno expresado en la Declaración, - que reduce la soberanía a la conformación de la ley-, la democracia contemporánea se fundamenta como un derecho. Los antiguos romanos habían distinguido la ley (lex) del derecho (jus), es decir, entre el mandato prescriptivo y lo que es justo. La democracia directa no es prescriptiva, sino un derecho potestativo. En este sentido se expresa el Pacto Internacional de Derechos Civiles y Políticos, -suscrito por la mayoría de las naciones del orbe-, promulgado el 16 de diciembre de 1966 por la Organización de las Naciones Unidas (ONU, 1966) en cuyo artículo 25, sección a), se otorga a todos los ciudadanos el derecho y la oportunidad de "Participar en la dirección de los asuntos públicos, directamente o por medio de representantes libremente elegidos" (p. 11). Como es notorio, el derecho a participar directamente es discrecional y no se reduce a votar ni a elaborar leyes, sino que se amplía a dar dirección de cualquier asunto público. De ahí que la solicitud de plebiscitos, iniciativas ciudadanas de ley, consultas populares, convocatorias para establecer revocatorias y cualquier otro mecanismo de participación, estén contempladas como posibilidades de la democracia directa. 
No obstante, el principal riesgo de la democracia directa es la inercia representativa que lleva a concebirla dentro de los límites de la mera aprobación o desaprobación de leyes o representantes políticos, pues evita la deliberación. Los casos privilegiados que procuran superar el partidismo político, la revocatoria de mandato para los representantes o la elección de candidatos independientes, se hallan también dentro del modelo representativo. Otros instrumentos sólo son utilizados para la promoción, aceptación o rechazo de leyes, lo que también resulta reduccionista; pues el referendo, el plebiscito y la consulta popular no resultan democratizadores en la medida que, sin oportunidad de deliberación, se limitan a manifestar electivamente un "no" o "si" a formulaciones previamente establecidas.

\section{Las estructuras representativas}

La inercia representativa constituye al gobierno del pueblo a través de representantes que formulan las políticas públicas. Las estructuras representativas tienen un amplio espectro: presidenciales o parlamentarias (Linz y Valenzuela, 1994/1997; Mainwaring, 1995); mayoritarias o consensuales (Lijphart, 1999/2000); elitistas o pluralistas (Held, 1995/1997); minimalistas y maximalistas, pasando por las procedimentales y las posibles combinatorias (Dahl, 2005). Además, se aplica en escalas nacional, regional o estatal y municipal o de alcaldías.

Las estructuras representativas suponen representantes elegidos mediante el sufragio. Por ende, su instrumento mínimo es el voto. Por encima del voto debe existir la alternancia gubernamental; la igualdad de raza, género y condición minoritaria para votar o ser electo; la libertad de asociación, expresión y participación para conformar partidos políticos o asociaciones que promuevan las candidaturas independientes. En su umbral máximo está la reciprocidad entre representantes y representados (responsiveness), la rendición de cuentas (accountability), la transparencia y diversos modos de fiscalización.

Las instituciones representativas ejercen la representatividad en varias especies: de autorización (Pitkin, 1967/1972), de práctica normativa (Diggs, 1968), de figura (Didier, 2000), política (Sartori, 1999), institucional necesaria (Ferrajoli, 2007), fiduciaria (Bobbio, 1999) o fideicomisaria (Rehfeld, 2009). La representación fiduciaria, como podría llamarse comprehensivamente a todas estas versiones, consiste en representar a los ciudadanos con poder y autoridad para actuar en su nombre sin ninguna obligación de conducirse recíprocamente de acuerdo a sus intereses y deseos (responsiveness). En contraste, la expresión máxima de representatividad consiste en la representatividad delegativa, es decir, donde los representantes actúan con poderes explícita- 
mente limitados y en condición de revocables. La expresión máxima presenta la dificultad de precisar y jerarquizar las preferencias de los representados; de ahí la necesidad de la comunicación y la deliberación por encima de los métodos de votación de la esquemática mayoría simple.

En la práctica, los alcances ciudadanos en las estructuras representativas están limitados a cambiar de representantes hasta las siguientes elecciones. Como los representantes poseen autonomía para tomar decisiones hay un nulo ejercicio de la deliberación (Manin, 1997) dada la sujeción a los intereses de su grupo parlamentario y, consecuentemente, se provoca la indiferencia hacia las preferencias de sus representados. Estas circunstancias provocan ilegitimidad en la autoridad y la profunda desafección ciudadana hacia la participación.

La ilegitimidad se causa porque, en la expresión de Gianfranco Pasquino (1988): "los partidos de gobierno han expropiado a los electores su influencia política" (p. 25). Es decir, han ejecutado un proceso de oligarquía y burocratización conocida desde hace más de un siglo como la "ley de hierro" (Michels, 1911/2008), por la cual los representantes son elegidos con métodos establecidos por ellos mismos, las elecciones se hacen de una lista cerrada de candidatos y, una vez instaurados, amplían las reglas de su oligarquía: el clientelismo, el patrimonialismo y el corporativismo.

La desafección ciudadana surge como distanciamiento recíproco entre representados y representantes dado que "[ los partidos políticos] se vuelven progresivamente menos sensibles a las necesidades de sus propias asociaciones, lo que a su vez refuerza la impresión de que el liderazgo de los partidos políticos le preocupa poco a los activistas del partido" (Tormey, 2015, p. 114). Los ciudadanos, por su parte, cada vez tienen menos afiliaciones partidistas. Los datos de Peter Mair e Ingrid Van Biezen (2001) e Ingrid Van Biezen, Peter Mair y Thomas Poguntke (2012) muestran que en Europa ha descendido la filiación de la población votante del 30 por ciento al 10 por ciento en las últimas cinco décadas.

De igual manera, el interés por informarse y participar dentro de los modelos tradicionalmente representativos presenta un declive generalizado (Vromen, 2003). Si se focaliza la atención en la América Latina contemporánea se hallará que "según los últimos datos de la CEPAL, la gente que cree más o menos en los partidos políticos está en el 20\%" (Castells, 2012) y "Las encuestas muestran que entre el 50 por ciento y el 80 por ciento de los ciudadanos, según países, no se consideran representados por partidos y gobernantes y ponen en cuestión las reglas institucionales de funcionamiento democrático" (Castells, 2014). No obstante, cabe advertir que las instituciones representativas no deben concebirse reduccionistamente a los partidos políticos y las cáma- 
ras parlamentarias. También la ciudadanía posee espacios en los tribunales electorales, en los organismos gubernamentales autónomos como consejos de judicatura, de transparencia, de auditorías ciudadanas y un largo etcétera. Gracias a lo cual la participación ciudadana puede realizar "una política que no confunda lo público con lo institucional, y que entienda que se puede defender lo público (los intereses generales) desde la comunidad" (Subirats, 2011, p. 93). Es decir, la democratización de la esfera pública tiene muchas oportunidades para dar cabida a las posibilidades participativas.

\section{Las oportunidades participativas}

A pesar de la desafección general de la ciudadanía, los espacios de participación emergen como alternativas para paliar las insuficiencias representativas. Según Maurice Duverger (1955/1980, p. 80 y ss.), la democracia directa se consideraría como la colaboración entre ciudadanos y representantes a través de la iniciativa popular y el referéndum. La colaboración más idónea entre representantes y representados tendría que rebasar la incidencia de estos instrumentos y establecerse como participación e involucramiento directo al modo de gobernanza.

Las fronteras entre participación y gobernanza ameritan precisarse. Desde la clasificación de Salvador Martí I Puig, Reynaldo Ortega y María Fernanda Somuano (2011) se categorizan las participaciones ciudadanas en electorales y no electorales. Éstas últimas incluyen: la no convencional (mítines, caravanas, peticiones, reparto de volantes); la disruptiva, que muestra insatisfacción y rechazo hacia el estatus quo (ocupación de plazas y edificios públicos, bloqueos, intentos violentos de derrocamiento); y la convencional (actividades comunitarias, contacto con las autoridades, militancia en organizaciones civiles, conformación de comités o comisiones ciudadanos, etc.).

La participación no electoral convencional posee buenas cualidades cívicas: valora positivamente la organización política y social y se adhiere a sus reglas (Vallès, 2000). Es decir, apunta a desarrollar actividades institucionalizando procedimientos, sobre todo al adquirir estructura organizacional - con intención permanente-, dentro de las administraciones gubernamentales en las cuales todavía depositan amplia credibilidad (Ganuza y Francés, 2015). Influye en el gobierno, con interacciones ante y con el Estado planteadas desde ambos lados de la interacción y no contra el gobierno.

La gobernanza es una instrumentación colaborativa del poder ciudadano en el gobierno. En consecuencia, posee mayor capital social y capacidad de participación ciudadana que la mera gobernabilidad. Busca nivelar la asimetría de poder que los partidos políticos cooptaron al convertirse en bloques herméticos y cuya misión se redujo a la eficacia de la contienda electoral. 
En la gobernanza las redes sociales provocan mayor simetría entre los ciudadanos y el Estado, pues la participación se ejerce por vía de la petición popular, la colaboración y hasta la delegación de acciones estatales. Joan Prats (2005) acota que: "La Comisión Europea, en la preparación de su Libro Blanco sobre la Gobernanza de 2001, adoptó la visión de que el modelo de gobernanza por redes se adaptaba mejor que los modelos jerárquicos tradicionales" (p. 162).

La gobernanza libera a la democracia participativa del yugo de una mera administración pública o nueva gestión estatal compartida. Es decir, la participación de actores públicos y privados no sólo proveerán servicios, sino también definirán las políticas públicas y los valores e indicadores de su evaluación. Entre esos valores se encuentran la acción en red, la inter-organización cooperativa que provoca el reequilibrio de las asimetrías del poder. Entre los indicadores, se exige la actualización electrónica del gobierno por las demandas de la sociedad digital.

Sin embargo, la participación se enfrenta a limitaciones de tiempo (el plazo determinado para concretar la propuesta de un plebiscito o la redacción de una iniciativa ciudadana), de espacio (para reunir asambleas ciudadanas), de origen (la estipulación de la instancia promovedora desde ciudadanos bien comunicados o representantes que saben de las necesidades de los electores), de extensión demográfica (por el número de solicitantes o participantes requeridos), de vinculación legal (de la obligatoriedad en la participación y de las formalidades para hacer imperativos los resultados participativos) y, en especial, la complejidad y especialización de la información de los asuntos. Ante todas esas limitaciones, las TIC están en posibilidad de aportar la participación en las instituciones representativas, como se verá al describir la Democracia Líquida.

\section{Democracia líquida: el espacio deliberativo de las TIC y su presencia en las instituciones políticas}

La Democracia Líquida tiene una denominación fácilmente vinculable con las aportaciones de Zygmunt Bauman (2000/2003) porque el renombrado sociólogo adjudicó el adjetivo "líquido" a diversas realidades (la modernidad, el amor, la vida, el miedo, el tiempo, el arte, la cultura, la sensibilidad, la vigilancia, etcétera) para señalar su contemporánea condición efímera, frágil, vertiginosa o versátil. Es cierto, "lo líquido" hace alusión a algo versátil, pero no necesariamente frívolo, banal o del todo frágil. Además, las contemporáneas condiciones de lo líquido se refieren prioritariamente a lo local en vez de lo global, a lo regional en lugar de atender lo mundial o universal. 
La Democracia Líquida coincide con los aspectos mencionados parcialmente en versatilidad y rapidez, pues no concibe a los representantes políticos o a las instituciones parlamentarias como realidades fijas e inamoviblemente sólidas hasta los cambios o reemplazos correspondientes por nuevas elecciones o reformas. Concibe el ejercicio y comunicabilidad delegativa de la soberanía en una mutabilidad y expedita adaptabilidad a las múltiples necesidades de las peticiones, la agenda pública, a los ajustes y co rrecciones que ofrecen los plebiscitos, los referendos y las revocatorias tan pronto sean urgentes, sin esperar a los plazos electorales o los períodos fijos del quehacer legislativo parlamentario.

La Democracia Líquida es una nueva denominación en proceso de consolidación para un constructo conceptual del modelo que busca - al incluir las TIC y programas de software en el quehacer político comunicativo y deliberativo de los ciudadanos- la síntesis de los modelos representativos y directos, es decir, la inclusión de la participación en lo comunitario con un sentido más responsable que la mera inserción del voto electrónico en el ámbito electoral. Su nomenclatura se ha derramado hasta los espacios de Wikipedia en español y francés. En las versiones inglesas y alemanas, a través de la plataforma P2PFWiki y bajo la denominación delegating voting, respectivamente. En la esfera académica su aparición es cada vez más frecuente en artículos, capítulos de libros y memorias de congresos, publicados en diversos idiomas entre los que se cuenta el español, el francés, el inglés, el alemán y también el ruso. Desde 2014 ha sido explicada y promovida por el The Liquid Democracy fournal (http://www.liquiddemocracyjournal.org) desde Berlín. No obstante, el concepto político en sí mismo es anterior a su actual denominación y puede rastrearse bajo otras modalidades (Behrens, 2017). En los ambientes de la ciencia política se le conoce como democracia deliberativa, votación proxy, democracia delegativa o contemporáneamente como democracia por internet, democracia digital o tecnopolítica (Kurban, Peña-López y Haberer, 2016), también como "e-Dem" haciendo referencia a la abreviación en inglés de la expresión "democracia electrónica" (como por ejemplo lo referencia la revista académica JeDEM que significa efournal of eDemocracy and Open Government, disponible en: http://www.jedem.org/index.php/jedem).

Consiste en el modelo de organización política por el cual los ciudadanos no declinan su soberanía en representantes políticos durante períodos fijos, sino que la ejercen o delegan de varias formas. El caso de la delegación soberana no corresponde a una representación política fiduciaria, es decir, se elige a representantes con condiciones vinculantes, imperativas y solidarias con las preferencias de los representados. De modo que los representantes en las cámaras no podrían conducirse por sí mismos o abstenerse a menos que sus electores así lo indiquen. 
El modelo líquido promueve la potestad de sustituir la representación política (de tipo fiduciario o declinación) por la delegación, es decir, un ciudadano tiene la alternativa de participar directamente o depositar en otro su soberanía para que su depositario (denominado representante o apoderado proxy) actúe en el sentido o la intención que le es encomendada de manera imperativa. O si fuera el caso, para que el proxy lo haga de conformidad a su parecer - si se encuentra autorizado para ello-, en el entendido que la delegación de la soberanía puede serle revocada en cualquier momento para que regrese al ciudadano originario. El apoderado proxy también puede delegarse en otro proxy si lo considera más adecuado o competente y está autorizado para ello por el ciudadano originario. Un representante proxy ideal es un representante ad hoc al que se le delega de manera potestativa el poder soberano para que se encargue exclusivamente de los asuntos en que se reconoce su especialidad o por la confianza en su probidad. El representante proxy es un apoderado de la soberanía y voto del ciudadano que hará uso de tales poderes en el sentido que se le indique. De esa forma, el representante proxy ideal obra con total transparencia frente a los intereses de los electores. No obstante, lejos del ideal, los motivos para seleccionar a un proxy pueden ser varios: desinterés en participar directamente, falta de tiempo para ilustrarse y participar en los asuntos directamente o el reconocimiento de que el representante participará políticamente mejor que el representado. En el caso ideal, el apoderado proxy puede recibir delegaciones acumuladas, es decir, además de contar son su voto y con el voto de quienes lo eligieron directamente, puede recibir la delegación de otros representantes proxies de ciudadanos comunes. De manera que es posible provocar proxies de proxies formando cadenas con mayor fuerza para una decisión final. En ello hay una posibilidad importante para la transparencia electoral: cada ciudadano puede hacer pública la razón por la cual elige a su representante proxy aludiendo a que otros ciudadanos se sumen a su selección.

Aunque, en la actualidad, debido al desarrollo de legislaciones que protegen los datos de particulares y la confidencialidad, se establece el debate sobre la potestad de hacer pública o no la deliberación para elegir a un proxy. También es importante recordar que un representante proxy está sujeto a la revocatoria de su representatividad una vez que el asunto encomendado haya sido zanjado o en cualquier momento de la deliberación parlamentaria, -antes de las decisiones definitivas-, si sus electores deciden representarse por otro proxy o por sí mismos. El representante proxy es un apoderado que actúa en nombre y por cuenta de los representados y no sólo a cuenta de quien le delegó su poder. Por tanto, no es un representante político tradicional que actúa en nombre de sus representados sin las obligaciones de la transparencia, la rendición de cuentas y el riesgo de la revocatoria inmediata, es decir, sin la obligación de ser representante solidario. De manera que, para los proxies, el compromiso de su re- 
presentatividad es vinculante y los convierte en co-responsables. Por ello y para ello son, en cualquier momento del proceso parlamentario, revocables.

La soberanía, en el modelo líquido, se ejerce no sólo para elegir a un apoderado proxy ad hoc al caso requerido en la agenda política, sino también para deliberar sobre los asuntos públicos y los mejores apoderados, para participar en la elaboración de las políticas públicas, decidir y ejecutar planes y programas de acción.

En concreto, la Democracia Líquida puede realizarse en una o varias combinaciones de las siguientes alternativas: (1) el ciudadano puede representarse a sí mismo, por medio de la presencia electrónica, en las cámaras o parlamentos; sobre todo en los procesos definitorios y decisorios de las políticas públicas a través del voto electrónico; (2) el ciudadano puede representarse a sí mismo participando electrónicamente con la contabilización de su parte proporcional de soberanía (o sumando las partes proporcionales de quiénes lo hayan elegido como apoderado proxy) en el escaño correspondiente a la representación o representante de su distrito electoral o político o, en su defecto, en el espacio correspondiente al partido político electo de su circunscripción. El partido debería adoptar la modalidad líquida, es decir, cuyos miembros partidistas aceptan que su presencia en la cámara o parlamentos será desplazada por la presencia electrónica de los electores o que su presencia obedece a la función vinculante e imperativa entre los electores y las resoluciones parlamentarias que adoptaran; y (3) hacerse representar a través de proxies ad hoc en todo tipo de asambleas según el asunto y diseño de la agenda política.

La primera y la tercera alternativa de la Democracia Líquida, aunque con ausencia de los medios y tecnologías electrónicas, formalmente nacieron en la Constitución francesa de 1793, en cuyo artículo 29 se estableció que "cada ciudadano tiene el mismo derecho para concurrir a la formación de la ley y al nombramiento de su mandatarios o agentes”. Esta formulación difiere sutil, pero poderosamente, de la Declaración de 1789. Según la Declaración de 1789 se puede acudir a la formación de ley o dejarla en manos de los representantes, mientras que la Constitución francesa de 1793 permite formar la ley y nombrar a los agentes mandatarios, es decir, a apoderados proxies ad hoc. No es lo mismo un representante (sobre todo si es fiduciario) que un mandatario o agente como apoderado vinculado y revocable. En el modelo líquido, además, no se está forzado a sostener por un período fijo a los apoderados proxies. El proyecto español Democracia 4.0 (Jurado, 2013), todavía por consolidar en la práctica, ilustra esta primera alternativa viabilizada por las tecnologías de comunicación electrónicas. La propuesta de Jan Van Dijk (2000) denominada Democracia libertaria y concebida como democracia plebiscitaria, -inspirado en la autonomía democrática de David Held 
(1987/1991) - es otro modelo que postula a la participación ciudadana a través de las TIC de manera que eliminan las funciones de los representantes.

La segunda alternativa de la Democracia Líquida se encuentra ejemplificada por los partidos líquidos. Destaca el Partido Pirata Internacional (https://pp-international.net. Así como https://partidopirata.org/). Este partido, fundado en 2006 en Suecia y Alemania, en el año 2009 alcanzó dos escaños en el Parlamento de la Unión Europea; en 2012, dos senadurías nacionales en la República Checa e Islandia; en 2014 alcanzó en Alemania 251 escaños locales y uno en el Parlamento de la Unión Europea; en octubre de 2016 se convirtió en la tercera fuerza política de Islandia. Cada legislación territorial puede condicionar, de modo anónimo o público, la delegación recibida en la representación de los miembros o espacios partidarios en las cámaras. En términos coloquiales, los partidos líquidos son piratas porque no reconocen el "derecho reservado" (como derecho de marca) para hacer política que los representantes fiduciarios aprovechan sólo para sí o que los representantes de partidos ejercen bajo el corporativismo partidista con indiferencia de su electorado. En España pueden enumerarse los proyectos no consolidados del Partido X (https://partidox.org/) y del Partido de Internet (https://www.facebook.com/Partido-de-Internet-PDI-168786883166140/), así como la organización interna y responsabilidad militante que declaran los partidos Podemos (https://podemos.info/) y Barcelona en Comú (BComú; https://barcelonaencomu.cat/). En Italia puede ejemplificarse con el Movimiento 5 Estrellas (http://www.movimento5stelle.it/) y en la Argentina con la propuesta de El Partido de la Red (http://partidodelared.org/). En todos los casos, las tecnologías de información y comunicación funcionan para establecer las vías deliberativas de participación al superar las limitaciones de espacio y tiempo.

Respecto a la tercera alternativa, Bryan Ford (2002, 2014) y Björn Swierczek (2014) consideran que la Democracia Líquida nació teóricamente en 1884 por la propuesta de Charles Dodgson (mejor conocido como el literato Lewis Carroll) en el texto Los principios de la representación parlamentaria. Dodgson explica la votación proxy como una delegación del voto que puede ser transitiva, es decir, temporal y transferible. La propuesta nació de las inquietudes para obtener un método capaz de seleccionar a los mejores candidatos, conseguir la representación más justa y también la defensa de las preferencias minoritarias. Otros autores (Paulin, 2014) consideran que la Democracia Líquida, bajo denominaciones como democracia deliberativa o votación por proxy, nació en 1912 cuando William S. O’Ren demandó una representación interactiva al exigir ponderar la cantidad de votos a cada representante proxy. El método de ponderación fue diseñado por Gordon Tullock en 1967, quien además propuso la participación directa mientras los debates parlamentarios deberían transmitirse por televisión. De esa 
forma los electores podían inclinarse por el representante más afín a sus preferencias. Hoy en día eso se puede hacer inmediatamente a través de las plataformas electrónicas, (como lo hizo el 12 de septiembre de 2013, el diputado español Joan Baldoví al disponer de su curul en el sentido de la votación abierta que en Internet convocó a sus electores). En 1969 James C. Miller, siguiendo a Tullock, argumentó sobre el derecho a votar cualquier cuestión en representación de sí mismo o a través de un representante ajeno al parlamento. Así, los representantes proxies son los apoderados, ajenos a los parlamentos o cámaras, sin filiación a partidos, en quiénes se delega, - no se declina-, la soberanía de cada elector para empoderarlos suficientemente con objeto de definir las políticas públicas.

De esta tercera alternativa también puede citarse la Constitución Ciudadana de Islandia, que fue aprobada por el referéndum de octubre de 2012. La carta magna, que lamentablemente sigue detenida en el parlamento (según la relatoría del Partido Comunista Obrero Español, 2013), se elaboró en una plataforma electrónica de participación y cooperación. En dicha plataforma participó una muestra obtenida por sorteo de ciudadanos voluntarios. La participación fue voluntaria, aunque la colaboración final estuvo condicionada al resultado del sorteo. La construcción de la Constitución de Islandia muestra una mezcla de la primera y tercera modalidades aquí descritas de la Democracia Líquida, pues en parte algunos ciudadanos se representaron a sí mismos al proponerse como voluntarios, otros resultaron representantes de correligionarios -al menos por sorteo- y quienes no participaron en el grupo voluntario dejaron a los conciudadanos como proxies de manera tácita. La misma fluidez del modelo líquido obliga a experimentar con casos empíricos que, como todo modelo múltiple, presenta combinatorias que no son universales ni fijas. En consecuencia, todavía algunas de las alternativas están alejadas de hallarse jurídicamente reconocidas.

Ahora bien, la Democracia Líquida en sus modalidades (2) y (3) alcanza la participación en las instituciones de representación consiguiendo, al menos en la delegación, la deliberación que requiere la cabalidad del modelo directo. La modalidad (1) desplaza a las instituciones representativas en la proporción que los ciudadanos intervengan directamente. Este caso existe en la incipiente experiencia de los parlamentos abiertos (Faria, 2012) y algunos intentos de los parlamentos electrónicos (Fallon, Allen y Williamson, 2011; Leston-Bandeira \& Bender, 2013; Setälä y Kimmo, 2006; Williamson, 2010). En Chile quedaron registradas las experiencias llamadas Senador Virtual, implementada en 2003 y el Chat de los senadores, aplicado de septiembre de 2004 a mayo de 2005 por iniciativa del entonces presidente del Senado Hernán Larraín. Ambas resultaron rudimentariamente exitosas porque privaron de una profunda deliberación y su correspondiente vinculación, omisiones que no ayudaron a su persistencia (Araya y 
Barría, 2009). Por lo cual puede conjeturarse que la modalidad (1) se encuentra más cerca de ser una realidad en la medida que alcanza mejores prácticas a través de la modalidad (2). Con lo cual, la participación, en efecto, se desdobla en modos semi-directos y semi-representativos.

El modelo líquido busca la complementariedad de los modelos participativos y representativos, superando las limitaciones que advirtió Luigi Ferrajoli (1989/1995):

En ausencia de democracia directa, en efecto, la democracia representativa únicamente puede valerse de un consenso vacío y pasivo y se halla expuesta a todas las aventuras y perversiones posibles. En ausencia de democracia representativa, la democracia directa está destinada a replegarse sobre sí misma, reproduciendo en su interior las formas de la representación y sucumbiendo a largo plazo por defecto de garantías jurídicas y políticas. (p. 948)

Por lo tanto, la democracia directa sin la deliberación líquida es arbitraria y tiende a ser caótica y la democracia representativa sin las aportaciones directas puede caer en mero procedimiento sin dar lugar a la sustancialidad de la soberanía ciudadana. Joan Subirats (2011, p. 59) ha insistido en que la democracia directa no funciona con referendos instantáneos y sin deliberación. De ahí la necesidad de incluir en las instituciones de representación a la deliberación con acciones más democratizadoras que el simple "no" o "sí" del referendo, la revocación o la consulta con categorías preestablecidas.

La inclusión de las TIC a los procesos democráticos incluye aspectos multidimensionales que no siempre se alcanzan a precisar o distinguir entre sí. Por ejemplo, puede existir confusión entre los denominados open government, el gobierno electrónico y la democracia electrónica. Si bien pueden distinguirse (Aguirre, 2016), por razones de espacio este ensayo se limita a las preguntas planteadas en la introducción.

Para contribuir a un mayor empoderamiento ciudadano, los instrumentos cibernéticos deben cumplir condiciones de dos tipos: políticas y comunicativas. Las primeras quedarían solventadas al permitir los mecanismos de participación directa fundamentados política y jurídicamente desde la Declaración de 1789 hasta el Pacto de 1966 ya citados. Las condiciones comunicativas están establecidas en el desarrollo de la versión web 2.0 y 3.0, tanto de las plataformas electrónicas como de las redes sociales. Las plataformas permiten las decisiones y el control de la gestión de recursos y necesidades comunitarias de manera cooperativa y compartida. Prueba de ello es la innovación cooperativa y la creación de cultura colectiva en espacios cibernéticos como Wikipedia, Flickr, CreativeCommons, share, academy, researchgate y un largo etcétera. Por su parte, las redes sociales (chats, foros, blogs, Facebook, Twitter) posibilitan la interacción deliberativa para construir el ágora digital. Ambas, plataformas y redes, apuntan a la 
asamblea cibernética. En el modelo líquido el parlamento virtual ad hoc se construye por los participantes que se hacen presentes según potestad o por delegación o delegaciones secuenciales. En la nueva ágora digital, asamblea cibernética o parlamento virtual, es decir, en la res publica gaseosa participa cualquier ciudadano interesado o los reconocidos expertos proxies a quiénes se les delegó la soberanía.

La construcción del ágora digital y sus efectos en la definición de las políticas públicas está en proceso de consolidación con un sinnúmero de softwares que ya son aplicados por movimientos sociales, partidos políticos y gobiernos. Destaca "AgoraVoting" como plataforma del voto líquido delegativo, revocable y transferible (secreto o no, según el deseo de hacerlo público para que otros ciudadanos también deleguen su representación en el proxy de mayor persuasión). Este método, junto con Democracy Os es utilizado por el partido Barcelona en Comú (BComú) que ganó las elecciones municipales de 2015. También ha sido perfeccionado el método "Liquid Feedback" para incorporar el voto preferencial, presumiendo que puede incorporar un infinito número de participantes en un espacio de discurso finito y concluyente (Behrens y Swierczek, 2015). Es utilizado por grandes corporativos para llegar a consensos democráticos, como en 2016 lo hizo Google (Hardt y Lopes, 2015) con alta participación de sus colaboradores. "Appgree" es la aplicación gratuita para alcanzar consensos por grupos multitudinarios; y precisamente es la plataforma que utiliza el partido español Podemos. "Adhocracy" es otro software que ha destacado por sus capacidades deliberativas y de consenso, tal y como lo utiliza la Comisión Federal Parlamentaria sobre Internet y Sociedad Digital en Alemania.

\section{Discusiones}

Las condiciones políticas y comunicativas descritas enfrentan obstáculos comunes. Howard Rheingold (2000) visualizó que las TIC serían una nueva versión de la mercantilización de la esfera pública, además de estar sujetas al control sobre la banda ancha para vigilar y desinformar, ello por no aludir a la colonización y manipulación de los medios de Internet que siempre están en riesgo de ser expropiados.

Es decir, la construcción del ágora digital sobre la base de comunidades virtuales corre el mismo peligro que los avances tecnológicos anteriores a Internet. En su momento, la máquina de vapor, la electricidad y la televisión se mostraron como progresos que cambiarían al mundo. En efecto, lo cambiaron; pero no cumplieron la utopía política respecto a la prosperidad traducida en igualdad, equidad y un sinnúmero de soluciones para los problemas colectivos, porque fueron monopolizados en manos antidemocráticas. En ese sentido, las TIC también ejemplifican el arma de dos filos: 
pueden interconectar a los ciudadanos y vincularlos comunitariamente o pueden ampliar la brecha digital marcando cada vez con mayor severidad las diferencias de clase.

La Democracia Líquida, como proyecto político sustentado con los instrumentos de las TIC, no debe caer en el mito esperanzador de que las nuevas tecnologías resolverán los problemas políticos que las tecnologías anteriores no resolvieron. No se trata de adaptar la política a Internet, sino consolidar las transformaciones positivas de Internet en las estructuras del poder. Las TIC, no obstante la brecha digital, representan la diseminación del poder y el control ante la oligarquía que monopolizó a los mass media tradicionales.

Los propósitos democráticos son protegidos por las TIC en la medida que facilitan el acceso a la información y la movilización, a la vez que evitan la intermediación forzosa a través de los partidos políticos y las instituciones que han cooptado para sí lo público y lo comunitario al colonizar los medios masivos de comunicación tradicionales. Respecto al control sobre la banda ancha para vigilar y desinformar, Castells (2009), en un ensayo vinculador del poder y los medios de comunicación presentó una sorprendente aporía: "parecería lógico concluir que el poder reside en las redes de comunicación... Esta conclusión puede ser lógica, pero es empíricamente errónea” (p. 537). La afirmación de Castells obliga a especificar los anidamientos del poder en Internet, dado que no sostengo que el poder resida en Internet, sino que el usuario de Internet se empodera y dispersa el poder centralizado. Por ello, lleva al ciudadano al poder, gracias a su estructura nodal, es decir, su capacidad para conectar y crear redes.

El control central sobre la banda ancha es anulado por tres capacidades de Internet: el poder de conectar en red, el poder en red y el poder para crear redes. El primero es definido por Manuel Castells (2009) de la siguiente manera: "consiste en la capacidad de dejar que un medio o un mensaje entren en la red mediante procedimientos de filtro de acceso" (p. 538). El poder en red, continua el mismo autor (2009), "es la forma del poder que ejercen determinados nodos sobre otros" (p. 538). Ante lo cual queda explícito que el poder de conectar en red puede generar u omitir filtros de nodos o filtros de mensajes y por ello puede afirmarse que el medio no es el mensaje. Pues el filtro de mensaje no filtra los nodos ni sus redes. Es decir, se filtran los mensajes, pero no los medios y éstos finalmente transmitirán los mensajes.

El poder para crear redes, que puede originarse del poder de unos nodos sobre otros, según Castells (2009) "es la capacidad de configurar y programar una red" (p. 539). Este último poder desborda el control que los propietarios, directivos o gobierno tienen sobre los medios de comunicación en red porque se pueden detener los mensajes, pero no los medios mismos. En consecuencia, Castells (2009) afirma: "una vez en el 
ciberespacio, a la gente pueden ocurrírsele todo tipo de ideas, incluso la de desafiar el poder de las empresas, desmantelar la autoridad del gobierno" (p. 540). En realidad, no sucede que estas ideas ocurran al llegar al ciberespacio, sino por provenir de los déficits de representatividad democrática es que llegan al ciberespacio.

De cualquier forma, el poder para crear redes lleva a un nuevo poder: el poder de conexión. Este es, dentro de las definiciones de Castells (2009): "la capacidad para conectar dos o más redes diferentes mientras cada una sigue construyendo el poder en su ámbito respectivo" (p. 548). Internet, actualmente con y desde la Web federada y sindicada, permite que una propuesta política, un voto no contemplado dentro de la institucionalización del proceso electoral o una petición ad hoc, sea elevada hasta el gobierno con mucha presión.

Muestras de la incapacidad para controlar la banda ancha, vigilar y desinformar, se hallan en experiencias mundialmente conocidas. La petición de perdón a Intisar Sharif Abdallah, la mujer condenada a la lapidación en Sudán en 2012, muestra como Twitter expandió su poder viral y en menos de un mes Amnistía Internacional recopiló 75,715 firmas, con lo cual se revirtió el proceso judicial (https://twitter.com/amnistiaespana). Internet también logró burlar la censura del régimen chino cuando el prisionero Liu Xiaobo terminó por enterarse de su galardón al Premio Nobel de la Paz en 2010. Sin lugar a dudas, las más notorias son las filtraciones de WikiLeaks y las del caso llamado Panama papers, que invadieron y dañaron a consorcios comerciales, corporaciones financieras y, si bien no ha depuesto a gobiernos, ha mejorado la calidad de la política cuando logró remover a algunos gobernantes, entre otros, a quien fue primer ministro de Islandia hasta abril de 2016.

Por lo que concierne a la calidad democrática de los contenidos vertidos en los medios, la Democracia Líquida supera a los modelos existentes por los despliegues deliberativos. La premisa mayor de este argumento considera que el modelo que movilice más propuestas y genere mejores ideas sobre el bien común y sus respectivas políticas públicas resultará el mejor modelo democrático (Blum y Zuber, 2016). La premisa menor, por su parte, reconoce que el modelo deliberativo, en su modalidad líquida y sustentada sobre las ventajas de las TIC, moviliza y añade más ideas sobre el bien común y sus respectivas políticas públicas y, consecuentemente, por el debate deliberativo genera la suma de mejores ideas.

La objeción común a la deliberación estriba en que no se da en un contexto comunicativo neutro y puro. Adam Przeworski (1998/2001) sostiene que un debate público, libre y bien fundamentado se encuentra amenazado por las condiciones desiguales de acceso a la información y las diferencias de capacidad de raciocinio. 
De cara al alegato contra la imposibilidad de alcanzar consensos justos e igualitarios, Lincoln Dahlberg (2001a, 2001b, 2001c, 2007, 2014) ha buscado superar las objeciones con indicadores analíticos consistentes aplicables a los recursos deliberativos en Internet. Los indicadores analíticos positivos son: Reciprocidad, Validaciones externas e internas, Persuasión, Progreso, Respeto implícito y explícito. Los neutros: Posición y el Acceso a Internet. Los negativos son: Tematización monológica, Radicalización, Incivilidad o no respeto. Argumentos similares alega Jon Elster (1998/2001) para solventar la deliberación: propone el uso sucesivo de tres tricotomías: discusión, negociación y votación; agregación, transformación y tergiversación; razón, interés y pasión (como componentes humanos de la deliberación).

La igualdad democrática de los electores está protegida en la Democracia Líquida por la libertad de elegir delegados proxies apoderados. Además, a mayor capacidad de elegir apoderados más capaces - gracias a la opción revocatoria y de elegir proxies de proxies-, el procedimiento deliberativo mejora y el equilibrio de igualdad se reestablece.

Las TIC garantizan que, si se realizan las actividades participativas y deliberativas, queden solventadas las condiciones comunicativas de tiempo y espacio. El tiempo real y virtual, se sintetiza en los softwares de deliberación y de toma de decisiones preferenciales. Las limitantes de espacio, propias de las asambleas ciudadanas, quedan obviadas gracias a las plataformas electrónicas que ponen a disposición el ciberespacio multifuncional. La cantidad inconmensurable de participantes es incluida por el desarrollo de los nuevos softwares con el apoyo de la multiplicidad de métodos de elección, de selección de preferencias y elaboración de consensos.

No obstante, más allá de la consabida objeción de la brecha digital y/o política, cabe sospechar: ¿en qué medida la era digital transforma la democracia? Las respuestas pesimistas están en los cuestionamientos de Benjamín Barber (2006): “Hasta qué punto son democráticas las nuevas tecnologías de telecomunicación?”, cuya indagatoria concluyó: "Es la política quien hará democrática a la tecnología. La tecnología no hará democrática a la política. La política es lo primero por lo que hay que luchar para conseguir una tecnología democrática” (p. 26). Después de poco más de media década, y considerando que el desarrollo de la Web llegó hasta la versión 3.0 con la sindicación y federación, Gustav Lidén (2012) también cuestionó: “Is e-democracy more than democratic?" para responder: "la Democracia electrónica no puede ser por sí misma totalmente democrática si el sistema político en el que está incrustado no es democrático" (p. 85). Más recientemente Evgeny Morozov (2013/2015) descartó la Democracia Líquida al referirse a la delegación proxy: "los que saben menos, ¿cómo reconocerán a los 
que saben más, si ellos mismos no saben? Si ellos no saben, no pueden verificar o validar quién sabe más [...]No es fácil evaluar el saber de otro" (p. 133).

Parecería que el optimismo líquido cae en una petición de principio: para que la Democracia Líquida, inseparable de su instrumentación electrónica, sea viable, es condición que la democracia en sí misma resulte viable. Ante esto debe recordarse una de las lecciones de Giovanni Sartori (1993/2003): la auténtica democracia debe conciliar su realidad descriptiva con sus exigencias prescriptivas. Es decir, que la esencia de la democracia es una espiral donde los ciudadanos influyen en el perfeccionamiento de las estructuras políticas y éstas a su vez permiten una mejor y mayor participación ciudadana.

La respuesta anterior puede desarrollarse y precisarse al recoger el punto de vista de Francisco Jurado (2014), por el lado jurídico y de Ramón Queraltó (2000) por la parte comunicativa. Para Jurado las TIC promueven la auto comunicación por su horizontalidad y con ello se tiene el suficiente potencial para unir la legitimación institucional (es decir, la competencia electoral entre los partidos líquidos y no líquidos y la competencia entre los apoderados proxies) con la legitimación social (la colaboración de los ciudadanos entre sí y de ellos con los representantes políticos para elaborar y proponer leyes) y por ello puede configurar, potenciar y reconfigurar las prácticas políticas que parecían inamovibles.

Guardadas las debidas diferencias entre la ciencia jurídica y las ciencias de la comunicación, la tesis de Jurado sigue la estrategia de Queraltó -denominada el caballo de Troya al revés: el uso frecuente de plataformas y redes hasta convertirlas en rutinarias- hará imposible extirparlas y, por ende, excluirlas de sus efectos democratizadores. Jurado había escrito también en el 2013 que su construcción se aplicaba como un "Caballo de Troya, que una vez inserto en el sistema, puede acercar el objetivo de obtener el derecho al voto real y permanente [de los ciudadanos en los parlamentos] por medios telemáticos" (p. 136). Es decir, ambos pensadores, con el uso de la misma metáfora, afirman que las TIC no son neutrales ni instrumentos de mera información, pues tienen influencias en la vida social y política.

Ahora bien, es cierto que existen aspectos políticos que las TIC por sí mismas no pueden resolver. La vinculación, -entendida como el hecho de convertir en imperativos los resultados arrojados por los instrumentos participativos-, o la misma obligatoriedad de la participación. Estas son dimensiones ajenas a la información y la comunicación, aunque no a la deliberación y efectos producidos en el ágora digital que acaba por impactar a los parlamentos, sean estos digitales o no. 


\section{Recapitulación conclusiva}

Aún con los pros et contras (Rovinska, 2014) que envuelven a la Democracia Líquida, deseo abordar una última cuestión: ¿la transformación digital de la democracia es deseable? Sin duda, toda vez superado el control central sobre el poder para crear redes, la transformación digital apunta a la continuidad evolutiva desde el aspecto descriptivo hacia el prescriptivo en la tarea democrática.

Sin embargo, no puede suscribirse un "futuro perfecto" al fincar la creencia del progreso inmaculado en la era de las redes, como lo hace Johnson Steven (2012/2013), o confiar plenamente en "la riqueza de las redes", según Yochai Benkler (2015) como si en efecto las redes fueran la matriz de la riqueza de las naciones. Pero -más allá de las contribuciones al gobierno electrónico o la administración pública digital- tampoco cabe cerrar los ojos ante los aportes de la era digital a la democracia. Las TIC, entre otros aspectos, auxilian a incluir las preferencias de todos los electores, sin excepción de las minorías oprimidas, aún y contra la brecha digital, porque siempre habrá proxies que por afinidad identitaria defiendan a los oprimidos. Todas las voces pueden incluirse, tanto de manera ponderada como por el consenso general. Las TIC pensadas como red de participación política aumentan el conocimiento y le da más peso persuasivo. Aunque, por otro lado, si bien la Web y el consenso no garantiza la eficacia de las políticas públicas, a todos los ciudadanos los hace participes de su elaboración y, en esa medida, de su corresponsabilidad. Además, como expuse, la Democracia Líquida evita el caos de la democracia directa - sobre todo cuando cae en saturación- y también evade el vacío de la representatividad, sobre todo cuando ésta se pierde en lo procedimental.

La Democracia Líquida con la vertiginosa opción digital de participar directamente o a través de apoderados proxies fácilmente revocables, supera la sobrecarga de información y garantiza la deliberación. Cuanto más si desde el inicio se justifica de manera pública la delegación en un proxy revocable. Este aspecto obliga a la mejoría de la honestidad, a elevar el nivel de expertos de los proxies y evita la cooptación de partidos políticos, mega-proxies y la distorsión de la soberanía en el clientelismo o el patrimonialismo. Finalmente, pero no de menor importancia, las TIC ya están en el camino de construir algo que las futuras generaciones no cederán: nuevos modelos políticos sustentados en los bienes públicos digitales.

\section{Referencias}

Aguirre, Jorge (2016). La democracia líquida. Los nuevos modelos políticos en la era digital. Barcelona: Universitat Oberta de Catalunya. 
Araya, Eduardo \& Barría, Diego (2009). E-participación en el Senado chileno: ¿aplicaciones deliberativas?. Convergencia, Revista de Ciencias Sociales, 51, 239-268.

Barber, Benjamín (2006). ¿Hasta qué punto son democráticas las nuevas tecnologías de telecomunicación? IDP Revista de Internet, Derecho y Política, 3, 17-27.

Recuperado el 13 de mayo 2019 de: https://idp.uoc.edu/articles/10.7238/idp.v0i3.401/galley/3309/download/

Bauman, Zygmunt (2000/2003). Modernidad Líquida, México D. F.: F.C.E.

Behrens, Jan (2017). The origins of Liquid Democracy. The Liquid Democracy fournal, 5, 7-17. Recuperado de:

http://www.liquid-democracy-journal.org/issue/5/The_Liquid_Democracy_Jo urnal-Issue005-02-The_Origins_of_Liquid_Democracy.html

Behrens, Jan \& Swierczek, Björn (2015). A finite discourse space for an infinite number of participants. The Liquid Democracy Journal, 4, 42-52. Recuperado de: http:// www.liquid-democracy-journal.org/issue/5/The Liquid Democracy JournalIssue005.pdf

Benkler, Yochai (2015). La riqueza de las redes. Cómo la producción social transforma los mercados y la libertad. Barcelona: Icaria Antrazyt.

Blum, Christian \& Zuber, Christina (2016). Liquid Democracy: Potentials, Problems, and Perspectives. The fournal of Political Philosophy, 24(2), 162-182. https://doi.org/10.1111/jopp.12065

Bobbio, Nestor (1999). "Rappresentanza e interessi". En Teoria Generale della politica, editado por Michelangelo Bovero. Torino: Einaudi.

Castells, Manuel (2009). Comunicación y poder. España: Alianza Editorial.

Castells, Manuel (2012, septiembre). El poder en la era de las redes sociales. Nexos. Recuperado de: http://www.nexos.com.mx/?p=14970

Castells, Manuel (2014, enero-marzo). El poder de las redes. Vanguardia Dossier, 50, 715. Recuperado de: https://docplayer.es/50723665-El-poder-de-las-redessociales.html

Dahl, Robert (2005). Democracia. POSTdata, 10, 11-55.

Dahlberg, Lincoln (2001a). The Internet and Democratic Discourse: Exploring The Prospects of Online Deliberative Forums Extending the Public Sphere. Information, Communication \& Society, 4 (4), 615-633. https://doi.org/10.1080/13691180110097030

Dahlberg, Lincoln (2001b). Democracy Via Cyberspace. New Media \& amp Society 3, 157-177. https://doi.org/10.1177/14614440122226038

Dahlberg, Lincoln (2001c). Computer-Mediated Communication and The Public Sphere: A Critical Analysis. Journal of Computer-Mediated Communication, 7, 1-40. https://doi.org/10.1111/j.1083-6101.2001.tb00137.x

Dahlberg, Lincoln (2007). The internet, deliberative democracy, and power: Radicalizing the public sphere. International Journal of Media and Cultural Politics, 3(1), 47-64. https://doi.org/10.1386/macp.3.1.47/1 
Dahlberg, Lincoln (2014). The Habermasian Public Sphere and Exclusion: An Engagement with Poststructuralist-Influenced Critics. Communication Theory, 24(1), 21-41. https://doi.org/10.1111/comt.12010

Didier, Philippe (2000). De la représentation en droit privé. Paris: Librairie Genérale de Droit et de Jurisprudence.

Diggs, Bernad James (1968). Practical Representation. Nomos, 10, 28-37. https://doi.org/ $\underline{10.4324 / 9781315128450-2}$

Duverger, Maurice (1955/1980). Instituciones políticas y Derecho Constitucional. México: Ariel.

Elster, Jon (1998/2001). Introducción. En Jon Elster (Ed.), La Democracia Deliberativa (13-33). Barcelona: Gedisa.

Fallon, Fredy; Allen, Beccy \& Williamson, Andy (2011). Parliament 2020: visioning the future parliament. International comparison: Australia, Canada, Chile and the United Kingdom. London: Hansard Society

Faria, Cristiano Ferri Soares de (2012). O parlamento aberto na era da internet: pode o povo colaborar com o Legislativo na elaboraçãodas leis? Brasília: Câmara dos Deputados

Ferrajoli, Luigi (1989/1995). Derecho y razón: teoría del garantismo penal. Madrid: Trotta

Ferrajoli, Luigi (2007). Principia Iuris. Teoria del diritto e della democracia. Roma-Bari: Laterza \& Figli.

Ford, Bryan (2002). Delegative Democracy. Recuperado de: http://www.brynosaurus.com/deleg/deleg.pdf

Ford, Bryan (2014). Delegative Democracy Revisited. Recuperado de: http://bford.github.io/2014/11/16/deleg.html

Galleguillo, Ruben (2016). Ciudadanía y Democracia: los nuevos desafíos. Más poder local. Revista de Comunicación Política e Institucional, 28, 50-54.

Ganuza, Ernesto \& Francés, Francisco (2015). Citizen participation in Europe: a comparative analysis from the sociopolitical contexts. OBETS. Revista de Ciencias Sociales, 1, 235-260. https://doi.org/10.14198/obets2015.10.1.09

Hardt, Steve, \& Lopes, Lia (2015). Google Votes: A Liquid Democracy Experiment on a Corporate Social Network. Technical Disclosure Commons. Recuperado de: http://www.tdcommons.org/dpubs series/79

Held, David (1987/1991). Modelos de democracia. Madrid: Alianza.

Held, David (1995/1997). La democracia y el orden global. Madrid: Paidós-Ibérica Ediciones.

Jurado, Francisco (2013). Democracia 4.0: Desrepresentación en el voto telemático de las leyes. Revista Internacional de Pensamiento Político, 8, 119-138.

Jurado, Francisco (2014). Nueva gramática política. De la revolución en las comunicaciones al cambio de paradigma. Barcelona: Icaria \& Antrazyt

Kurban, Can; Peña-Lopez, Ismael \& Haberer, Maria (2016). What is technopolitics? a conceptual scheme for understanding politics in the digital age. Building $A$ European Digital Space. $12^{\text {th }}$ International Conference on Internet, Law and 
Politics, (pp. 499-519). Barcelona: Univesitat Oberta de Catalunya, Huygenes Editorial.

Leston-Bandeira, Cristina \& Bender David (2013). How deeply are parliaments engaging on social media? fournal Information Polity, 18(4), 281-297. https://doi.org/10.3233/ip-130316

Lidén, Gustav (2012). Is e-democracy more than democratic? - An examination of the implementation of socially sustainable values in e-democratic processes. EFEG, 10(1), 84-94.

Lijphart, Arend (1999/2000). Modelos de democracia: Formas de gobierno y resultados en treinta y seis países. Barcelona: Ariel.

Linz, Juan \& Valenzuela, Arturo (1994/1997). Las crisis del presidencialismo: Perspectivas comparativas. Madrid: Alianza Editorial.

Mainwaring, Scott (1995). Presidencialismo, multipartidismo y democracia: la difícil combinación. Revista de Estudios Políticos, 88, 115-144.

Mair, Peter \& Van Biezen, Ingrid (2001). Party Membership in Twenty European Democracies, 1980-2000, Party Politics, 7(1), 5-21. https://doi.org/10.1177/1354068801007001001

Manin, Bernard (1997). The Principles of Representative Government. Cambridge: University Press.

Martí I Puig, Salvador; Ortega, Reynaldo \& Somuano, María Fernanda (2011). La democracia en México. Un análisis a 10 años de la alternancia. Barcelona: Ediciones Bellaterra/ El Colegio de México.

Michels, Robert (1911/2008). Los partidos políticos. Un estudio sociológico de las tendencias oligárquicas de la democracia moderna. Buenos Aires: Amorrortu

Miller, James (1969). A program for Direct and Proxy voting in the Legislative Process. Public Choice, 7(1), 107-113. https://doi.org/10.1007/bf01718736

Morozov, Evgeny (2013/2015). La locura del solucionismo tecnológico. Buenos Aires: Editorial Katz.

Organización de las Naciones Unidas (ONU) (1966). Pacto Internacional de Derechos Civiles y Políticos. Nueva York: Autor.

Partido Comunista Obrero Español (2013). Islandia: radiografía de una revolución «ciudadana». Recuperadode: http://www.pcoe.net/actualidad1/actualidadinternacional/444-islandia-radiografia-de-una-revolucion-ciudadana

Pasquino, Gianfranco (1994). Shaping a Better Republic? The Italian Case in a Comparative Perspective, Madrid: Instituto Juan March de Estudios en Investigaciones.

Paulin, Alois (2014). Through Liquid Democracy to Sustainable Non-Bureacratic Government. JeDem, 6(2), 216-230. https://doi.org/10.29379/jedem.v6i2.298

Pitkin, Hanna (1967/1972). The concept of representation. California: University of California Press.

Prats, Joan (2005). Modos de gobernación de las sociedades globales. En Agustí Cerrillo (Ed.), La gobernanza hoy: 10 textos de referencia (pp. 145-172). Madrid: Instituto Nacional de Administración Pública. 
Przeworski, Adam (1998/2001). Deliberación y dominación ideológica. En Jon Elster (Ed.), La Democracia deliberativa (pp. 183-206). Barcelona: Gedisa.

Queraltó, Ramón (2000). El caballo de Troya al revés: diseño de una estrategia ética en la sociedad tecnológica. Actas del III Congreso de la Sociedad de Lógica, Metodología y Filosofía de la Ciencia en España. San Sebastián: Universidad del País Vasco.

Rehfeld, Andrew (2009). Representation Rethought: On Trustees, Delegates, and Gyroscopes in the Study of Political Representation and Democracy. The American Political Science Review, 103(2), 214- 230. https://doi.org/10.1017/s0003055409090261

Rheingold, Howard (2000). The virtual community: homesteading on the electronic frontier. Massachusetts : MIT Press.

Rovinska, Tatiana (2014). Liquid Democracy: Pro et Contra. Mirovaya ekonomika $i$ mezhdunardonye, 12, 60-69.

Sartori, Giovanni (1999). En defensa de la representación política. Claves de Razón Práctica, 91, 2-6.

Sartori, Giovanni (1993/2003). ¿Qué es la democracia? Madrid: Taurus.

Setälä, Maija \& Kimmo, Grönlund (2006). Parliamentary websites: Theoretical and comparative perspectives. Information Polity, 11(2), 149-162. https://doi.org/10.3233/ip-2006-0095

Steven, Johnson (2012/2013). Futuro perfecto: sobre el progreso en la era de las redes. Madrid: Ed. Turner.

Subirats, Joan (2011). Otra sociedad ¿otra política? Del "no nos representan" a la democracia de lo común. Barcelona: Icaria.

Swierczek, Björn (2014). Five years of Liquid Democracy in Germany. The Liquid Democracy fournal, 1, 8-19. Recuperado de: http://www.liquid-democracyjournal.org/issue/1/The Liquid Democracy Journal-Issue001-02Five years of Liquid Democracy in Germany.html

Tormey, Simon (2015). Democracy will never be the same again: $21^{\text {st }}$ Century Protest and the Transformation of Politics. Recerca, Revista de Pensamnet I Análisi, 17, 107-128. https://doi.org/10.6035/recerca.2015.17.6

Vallès, Josep (2000). Ciencia política. Una introducción. Barcelona: Ariel.

Van Biezen, Ingrid; Mair, Peter \& Poguntke, Thomas (2012). Going, Going,... Gone? The Decline of Party Membership in Contemporary Europe. European fournal of Political Research, 51(1), 24-56. https://doi.org/10.1111/j.14756765.2011.01995.x

Van Dijk, Jan (2000). Models of Democracy and Concepts of Communication. In Kenneth Hacker and Jan van Dijk (Eds.), Digital Democracy. Issues of Theory and Practice (pp. 30-53). London, Thousand Oaks CA, New Delhi: Sage.

Vromen, Ariadne (2003). 'People Try to Put Us Down...': Participatory Citizenship Of' generation X. Australian fournal of Political Science, 38(1), 79-99. https://doi.org/10.1080/1036114032000056260 
Williamson, Andy (2010). Digital citizens and democratic participation. An analysis of how citizens participate online and connect with MPs and Parliament. London: Hansard Society.

Este texto está protegido por una licencia Creative Commons 4.0.
Usted es libre para Compartir — copiar y redistribuir el material en cualquier medio o formato-y Adaptar el documen-
to — remezclar, transformar y crear a partir del material— para cualquier propósito, incluso comercialmente, siempre
que cumpla la condición de:
Atribución: Usted debe reconocer el crédito de una obra de manera adecuada, proporcionar un enlace a la licencia, e in-
dicar si se han realizado cambios . Puede hacerlo en cualquier forma razonable, pero no de forma tal que sugiera que tie-
ne el apoyo del licenciante o lo recibe por el uso que hace.
Resumen de licencia - Texto completo de la licencia

